\title{
1 Flow cytometric analysis and purification of airway epithelial cell subsets
}

2

3 Luke R. Bonser ${ }^{1,2}$, Kyung Duk Koh ${ }^{1,2}$, Kristina Johansson ${ }^{3,4,5}$, Semil P. Choksi ${ }^{2}$, Dan Cheng ${ }^{1,2,9}$,

4 Leqian Liu', Dingyuan I. Sun ${ }^{7}$, Lorna T. Zlock ${ }^{7}$, Walter L. Eckalbar ${ }^{1,8}$, Walter E. Finkbeiner ${ }^{7}$, and

5 David J. Erle $e^{1,2,8}$

6

$7 \quad{ }^{1}$ Lung Biology Center, ${ }^{2}$ Cardiovascular Research Institute, ${ }^{3}$ Department of Microbiology and

8 Immunology, ${ }^{4}$ Division of Pulmonary, Critical Care, Sleep, and Allergy, ${ }^{5}$ Sandler Asthma Basic

9 Research Center, ${ }^{6}$ Department of Bioengineering and Therapeutic Sciences, ${ }^{7}$ Department of

10 Pathology, and ${ }^{8}$ UCSF CoLabs, University of California San Francisco, San Francisco, CA

1194143 and ${ }^{9}$ Department of Respiratory and Critical Care Medicine, Renmin Hospital of Wuhan

12 University, Wuhan, China 430060

13

14 Running title: Flow cytometric analysis of the airway epithelium

15

16 Some of the results of these studies have been previously reported in the form of abstracts.

17

18 Contributions:

19 LRB and DJE contributed to study conception and design.

20 LRB developed novel experimental methods.

21 LRB, KJ, KDK, SPC, DC, LL, DIS, and LTZ performed experiments.

22 LRB, KJ, KDK, DC, LL, WLE, and DJE analyzed data.

23 LRB and DJE interpreted data.

24 WEF and DJE supervised study execution.

$25 \mathrm{LRB}, \mathrm{KDK}$, and DJE drafted the manuscript.

26 All authors revised the manuscript. 
bioRxiv preprint doi: https://doi.org/10.1101/2020.04.20.051383; this version posted April 21, 2020. The copyright holder for this preprint (which

was not certified by peer review) is the author/funder, who has granted bioRxiv a license to display the preprint in perpetuity. It is made available under aCC-BY-NC-ND 4.0 International license.

\section{Funding}

28 This work was supported by National Institutes of Health grants U19 Al 077439, R35 HL145235,

29 and R01 HL138424 (DJE); National Institutes of Health grant DK072517 and Cystic Fibrosis

30 Foundation grant DR613-CR11 (WEF); and, UCSF Program for Breakthrough Biomedical

31 Research Postdoctoral Independent Research Project Award (LRB). 


\section{Abstract}

33 The human airway epithelium is essential in homeostasis, and epithelial dysfunction contributes

34 to chronic airway disease. Development of flow cytometric methods to characterize subsets of

35 airway epithelial cells will enable further dissection of airway epithelial biology. Leveraging

36 single cell RNA-sequencing (scRNA-seq) data in combination with known cell type-specific

37 markers, we developed panels of antibodies to characterize and isolate the major airway

38 epithelial subsets (basal, ciliated, and secretory cells) from human bronchial epithelial cell

39 cultures. We also identified molecularly distinct subpopulations of secretory cells and

40 demonstrated cell subset-specific expression of low abundance transcripts and micro-RNAs that

41 are challenging to analyze with current scRNA-seq methods. These new tools will be valuable

42 for analyzing and separating airway epithelial subsets and interrogating airway epithelial

43 biology.

44

45 Keywords

46 Airway epithelium; single cell RNA sequencing; flow cytometry 


\section{Introduction}

48 Flow cytometry is a commonly used research and diagnostic tool that uses fluorophore-

49 conjugated antibodies as probes to identify, characterize, and/or isolate cell populations (1). The

50 immunology community has developed panels of antibodies useful for detailed

51 immunophenotyping of immune cells derived from many organs including the lung. A recent

52 American Thoracic Society working group report (2) heralded the importance of flow cytometry

53 in pulmonary research, but noted that "the development of appropriate markers for

54 nonimmunologic cells is less mature than other pulmonary cell types," including epithelial cells.

$55 \quad$ The airway epithelium defends against inhaled environmental challenges including

56 pollutants, pathogens, and allergens (3), and epithelial dysfunction is central to the

57 pathogenesis of major lung diseases including asthma, cystic fibrosis, chronic obstructive

58 pulmonary disease, and primary ciliary dyskinesia (4). Proximal airway epithelial subsets

59 including basal cells, ciliated cells, secretory cells including club and goblet cells, intermediate

60 cells, brush cells, and pulmonary neuroendocrine cells have been defined morphologically and

61 by their anatomical location within the tissue by histology and electron microscopy $(5,6)$. Single

62 cell RNA-sequencing (scRNA-seq) is further advancing our understanding of airway epithelial

63 heterogeneity. Recent studies of human and murine airways have confirmed the presence of

64 previously defined major airway epithelial subsets, identified molecularly distinct subpopulations

65 of these cells, and uncovered previously unrecognized cell types including ionocytes (7-11).

66 Pan-epithelial antibodies (EpCAM/pan-cytokeratin (12)) and limited sets of cell type-

67 specific antibodies (e.g., acetylated alpha-tubulin (TUBA) for ciliated cells (13), nerve growth

68 factor receptor (NGFR) and integrin subunit alpha 6 (ITGA6) (14) for basal cells, and mucin-5AC

69 (MUC5AC) for goblet cells (15)) have been used individually for flow cytometry. We sought to

70 develop a larger panel of antibodies for simultaneous analysis of the major subsets of airway

71 epithelial cells and provide a new tool for further understanding airway epithelial physiology and 
72 pathology. To this end, we used known markers described elsewhere in the literature,

73 augmented these by leveraging information from scRNA-seq datasets, and developed panels of

74 antibodies for flow cytometry to identify, characterize, and isolate the major human airway

75 epithelial subsets.

\section{Methods}

78 Additional details are provided in the online data supplement. A detailed protocol is provided in

79 the online supplementary document.

\section{Primary human bronchial epithelial cell (HBEC) culture}

82 HBECs isolated from lungs not used for transplantation were cultured at air-liquid interface (ALI)

83 as previously described $(16,17)$. We harvested cells 23 days after establishment of ALI. Some

84 cultures were stimulated with IL-13 $10 \mathrm{ng} / \mathrm{ml}$ for the final seven days of culture to induce goblet

85 cell production as indicated (18). The UCSF Committee on Human Research approved the use

86 of HBECs for these studies.

\section{Flow cytometry analysis}

89 We trypsinized HBECs to generate single cell suspensions and fixed cells in $0.5 \%(\mathrm{v} / \mathrm{v})$

90 paraformaldehyde; if not stained immediately, cells were frozen at $-80^{\circ} \mathrm{C}$. Cells were blocked,

91 stained with the analytical panel (Table E1), and analyzed by flow cytometry.

\section{Flow cytometry cell sorting}

94 Prior to trypsinization, cells were incubated in culture media containing SiR-Tubulin

95 (Spirochrome/Cytoskeleton Inc., Denver, CO). Single cell suspensions were generated as

96 above, and singlets stained with fixable viability dye eFluor450 (ThermoFisher Scientific, 
97 Fremont, CA, USA) to discriminate live cells. Cells were subsequently stained with a sorting

98 panel comprising cell surface markers only (Table E1) and sorted by flow cytometry.

99

100

\section{Gene expression analysis}

101 We isolated total RNA from sorted cells, performed reverse transcription, and analyzed the

102 cDNA by quantitative real-time PCR (qRT-PCR) to quantify specific mRNAs and microRNAs

103 (miRNAs). Table E2 lists qRT-PCR primer sequences.

\section{Results}

\section{Identification of airway epithelial subset markers}

107 To identify a panel of candidate cell-subset specific markers, we combined markers previously 108 used for flow cytometry (TUBA, ITGA6, NGFR, and ITGA6) with transcripts identified in several 109 recent human scRNA-seq datasets (cadherin-related family member 3 (CDHR3) and CEA cell

110 adhesion molecule (CEACAM) 5) (7, 9-11). We also analyzed HBECs differentiated at air-liquid

111 interface $(16,17)$ using the Drop-seq scRNA-seq platform (19); IL-13-stimulated cultures were

112 included as IL-13 induces goblet cell production (18) (Figure E1B). We examined our dataset for

113 cell-type-specific transcripts (Figure E1B), defined as genes more highly expressed in one cell

114 type than the others (FDR < 0.05) and identified two additional markers (CEACAM6 and

115 tetraspanin-8 (TSPAN8)). We combined all markers into a prospective flow panel (Table 1).

116 To test whether these putative cell subset markers were suitable for flow cytometry, we

117 stained unstimulated and IL-13-stimulated HBECs from 5 donors with antibodies against these

118 markers individually and performed flow cytometry. Each antibody stained a subset of HBECs

119 from both unstimulated and IL-13-stimulated cell cultures, except for the goblet cell markers

120 TSPAN8 and MUC5AC, which stained a subset of cells from IL-13-stimulated cultures, but few

121 if any cells from unstimulated cultures (Figure 1A). We observed significant increases in cells 
122 staining for TSPAN8 $(P=0.022)$, and MUC5AC $(P=0.0016)$ following IL-13-stimulation;

123 however, we did not observe statistically significant effects of IL-13-stimulation on the proportion

124 of cells stained for the other markers (Figure 1B).

125

\section{Characterization of airway epithelial cells subsets using an analytical antibody panel}

To define the relationships between cell subsets defined by these eight individual

128 markers, we performed multicolor flow cytometry with an analytical panel comprising all eight

129 antibodies (Table E1) on unstimulated and IL-13-stimulated HBECs from three donors. This

130 produced a 10-dimensional dataset (one fluorescence intensity for each of the eight antibodies,

131 forward scatter (FSC), and side scatter (SSC)). We analyzed this dataset with t-Distributed

132 Stochastic Neighbor Embedding (tSNE; Figure 2A-J). The distribution of marker staining

133 indicated that cell type heterogeneity was the major driver of staining patterns in this data set,

134 although effects of IL-13-stimulation (Figure 2K) and inter-donor variation (Figure 2L) also

135 contributed to the staining patterns. We next examined each staining parameter in relation to

136 the tSNE plot. TUBA staining (Figure 2A) was confined to a distinct cluster of cells that were

137 predominantly $\mathrm{CDHR}^{+}$(Figure 2B); cells bearing these two ciliated cell markers had little if any

138 basal or secretory cell marker staining. Another cluster comprised cells stained for the basal cell

139 markers NGFR (Figure 2C) and ITGA6 (Figure 2D), but with little if any secretory or ciliated cell

140 marker staining, except for a small subset that stained for CDHR3. Cells that stained for neither

141 ciliated nor basal cell markers generally stained with antibodies against one or both of the

142 secretory cell markers CEACAM5 (Figure 2E) and CEACAM6 (Figure 2F). CEACAM5 staining

143 was more pronounced in IL-13-stimulated cells. TSPAN8 and MUC5AC were detected only

144 after IL-13 stimulation. TSPAN8 staining was limited to a subset of CEACAM5 ${ }^{+}$cells (Figure

$1452 \mathrm{G}$ ); MUC5AC staining was confined to a subset of the TSPAN8 $^{+}$population (Figure $2 \mathrm{H}$ ).

146 Ciliated cells (TUBA ${ }^{+}$and $\mathrm{CDHR}^{+}$) and some secretory cells tended to have higher forward 
scatter (Figure 2I), an indicator of cell size, and basal cells $\left(\right.$ ITGA6 $^{+}$and frequently NGFR $\left.{ }^{+}\right)$

148 tended to have lower side scatter (Figure 2J).

To explore cellular heterogeneity, we examined the combination of the eight analytical

150 panel markers on individual cells. Figure 2M-Q and Figure E2 illustrate the use of a sequential

151 gating strategy to identify subpopulations of cells. Cells expressing the ciliated cell marker

152 TUBA were clearly distinct from those expressing the basal cell marker NGFR, and cells lacking

153 both TUBA and NGFR included subsets of cells expressing various combinations of the

154 secretory cell markers CEACAM6, TSPAN8, and MUC5AC that were markedly altered by IL-13

155 stimulation.

We considered all $2^{8}(256)$ possible combinations of staining that could be seen using

157 the panel of 8 markers and focused our attention on all subsets containing at least $1 \%$ of total

158 cells (Figure 2R and Table E3). In unstimulated HBECs, 12 such subsets were observed. After

159 IL-13 stimulation, we identified 17 subsets, 11 of which were present in unstimulated culture

160 conditions. Subsets expressing basal cell markers (NGFR ${ }^{+}$ITGA6 $^{+}, \mathrm{CDHR}^{+} \mathrm{NGFR}^{+} \mathrm{ITGA6}^{+}$, and

161 ITGA6 $^{+}$only) were identified in both culture conditions and their proportions were not

162 significantly changed by IL-13. TUBA ${ }^{+} \mathrm{CDHR}^{+}$cells and $\mathrm{TUBA}^{+}$only cells were also present in

163 both unstimulated and IL-13-stimulated cultures, although the TUBA ${ }^{+}$only subset was

164 significantly reduced following IL-13-stimulation. Four $\mathrm{TUBA}^{+} \mathrm{CDHR}^{+}$cell subsets that co-

165 stained with combinations of the secretory cell markers CEACAM6, CEACAM5, and MUC5AC

166 were also observed; three of these subsets were significantly increased by IL-13. Cells

167 expressing both ciliated and secretory cell markers have been also identified in scRNA-seq

168 experiments, with pseudotime analyses suggesting that these cells may represent a transition

169 from secretory to ciliated cells (11). Of cells bearing secretory cell markers,

$170 \mathrm{CEACAM6}^{+} \mathrm{CEACAM}^{+}$cells were present in similar proportions in unstimulated and IL-13-

171 stimulated conditions, as were CEACAM5 ${ }^{+}$only cells. CEACAM6 ${ }^{+}$only cells were unique to

172 unstimulated cultures. IL-13 stimulation led to the emergence of cells expressing both 
173 CEACAM5 and TSPAN8. These cells could be further subdivided into five subsets based on

174 expression of other markers. Three of the five CEACAM5 ${ }^{+}$TSPAN8 $^{+}$subsets also stained with

175 MUC5AC, as would be expected for goblet cells. Whether the CEACAM5 ${ }^{+}$TSPAN8 $^{+}$MUC5AC $^{-}$

176 populations represent goblet cell precursors, goblet cells that have secreted MUC5AC, or novel

177 IL-13-induced secretory cell subsets requires further investigation. Our findings are consistent

178 with bronchial tissue staining that demonstrated colocalization of CEACAM5 and MUC5AC in

179 never and current smokers (10). We also identified a subset that stained with none of the

180 markers (Null) and was present under both culture conditions. Collectively, these data suggest

181 IL-13 alters epithelial cell diversity, shifting populations towards cell subsets exhibiting secretory

182 and goblet cell markers.

\section{A modified flow cytometry panel is suitable for live cell sorting}

Flow cytometry is also useful for live cell sorting. Our analytical panel precludes this since it requires fixation and permeabilization for staining with antibodies against the intracellular antigens MUC5AC and TUBA. We therefore designed a sorting panel that omitted the MUC5AC antibody and replaced the TUBA antibody with SiR-tubulin, a membranepermeable live cell dye that stains microtubules (20), which have a major structural role in cilia (21). To ensure that we only sorted live cells, we also included a viability dye. The sorting panel 191 is detailed in Table E1.

To evaluate this panel, we performed flow cytometric cell sorting on unfixed HBECs from

1933 donors (Figure 3A-E). After excluding dead cells that failed to exclude the viability dye, we

194 gated on SiR-tubulin and NGFR and identified the SiR-tubulin ${ }^{+}$GFR $^{-}$singlets. Sorted SiR-

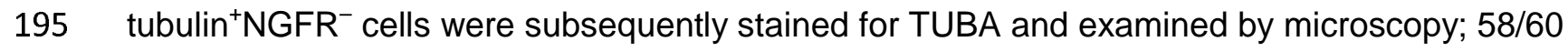

196 cells examined possessed cilia and stained with TUBA, confirming that these were ciliated cells

197 (Figure 3F and G). We gated the remaining singlets on CEACAM6 and NGFR staining to 198 discriminate between secretory and basal cell subpopulations. 
We sorted these three cell subsets from HBECs, isolated total RNA, and performed qRT-PCR for cell type-specific markers (Figure 3H). As expected, the ciliated cell transcripts forkhead box J1 (FOXJ1), tubulin alpha 1A class 1 (TUBA1A), and CDHR3 were enriched in the

202 SiR-tubulin $^{+}$ciliated cell subset. The basal cell transcripts cytokeratin 5 (KRT5) and NGFR were 203 enriched in the NGFR ${ }^{+}$basal cell subset; this subset also expressed ITGA6. The secretory cell

204 transcripts, secretoglobulin family $1 \mathrm{~A}$ member 1 (SCGB1A, also known as club-cell specific

205 protein, $C C S P)$ and mucin-5B (MUC5B), along with CEACAM6, were enriched in the

$206 \mathrm{CEACAM6}^{+}$secretory cell subset, as expected. The goblet cell transcripts SAM pointed domain

207 containing ETS transcription factor (SPDEF), MUC5AC, and TSPAN8 were upregulated in

208 CEACAM6 $^{+}$TSPAN8 $^{+}$cells from IL-13- stimulated HBEC cultures. Collectively, this analysis

209 demonstrated that the combination of cell surface marker and SiR-tubulin staining was sufficient

210 for discriminating the major airway epithelial cell populations.

Analyzing sorted cells may improve the ability to detect low abundance transcripts that

212 are difficult to quantify using available scRNA-seq approaches. We identified several transcripts

213 detected in a bulk RNA-seq dataset (22) but absent from our scRNA-seq dataset, and

214 performed qRT-PCR to determine their cell-subset-specific expression. For example, the

215 transcription factor SPDEF is critical for IL-13-induced goblet cell differentiation of HBECs (15)

216 but was not detected in our scRNA-seq dataset. Using our sorting panel, we found that SPDEF

217 was selectively expressed in CEACAM6 ${ }^{+}$secretory cells, particularly CEACAM6 ${ }^{+}$TSPAN8 $^{+}$cells

218 (Figure 3D). The alarmin thymic stromal lymphopoietin (TSLP) was almost exclusively

219 expressed in the NGFR ${ }^{+}$basal cell subset. The ciliated cell transcription factor MYB proto-

220 oncogene, transcription factor $(M Y B)(23)$ was expressed primarily in SiR-tubulin ${ }^{+}$ciliated cells

221 and was downregulated by IL-13. Expression of the secreted protein, proline-rich protein BstNI

222 subfamily 1 (PRB1), which we identified as an IL-13-induced gene by bulk RNA-seq but did not

223 detect using Drop-seq, was enriched in the CEACAM6 ${ }^{+}$TSPAN8 $^{+}$secretory cell subset. 
Analyzing sorted cells also allows for analysis of small RNAs, such as miRNAs, that are not assessed using Drop-seq and related scRNA-seq approaches. miR-34/449 family miRNAs

226 are required for motile ciliogenesis (24). We quantified miR-34c-5p and miR-449a and

227 confirmed enrichment in SiR-tubulin ${ }^{+}$ciliated cells. We found that miR-375, which is involved in

228 goblet cell differentiation in the colon (25), was IL-13-inducible, restricted to secretory cells, and

229 enriched in the TSPAN8 ${ }^{+}$secretory cell subset. These data demonstrate that the sorting

230 strategy we developed is useful for isolating and characterizing subpopulations of epithelial cells

231 with distinct transcriptional and miRNA profiles.

\section{Discussion}

234 Our study outlines an analytical flow panel and gating strategy for the characterization and 235 enumeration of subsets of airway epithelial cells from HBECs. We also demonstrate a scheme 236 for isolating common airway epithelial subsets from HBECs using a sorting flow panel. Both 237 panels identified the major airway epithelial subsets - ciliated cells, basal cells, and secretory 238 cells - as well as molecularly distinct subsets of each.

We identified several molecularly distinct, IL-13-regulated secretory cell subsets. IL-13-

240 driven changes included the disappearance of CEACAM6 ${ }^{+}$only cells, and the emergence of

$241 \mathrm{TSPAN8}^{+}$and MUC5AC ${ }^{+}$subsets, supporting evidence of IL-13-induced alterations in secretory

242 cell phenotype. We confirm that transcriptional heterogeneity in secretory cells is accompanied

243 by related changes at the protein level. Whether these subsets are functionally disparate or

244 represent novel subsets with overlapping function, and what epigenetic processes underlie the

245 shift in secretory cell heterogeneity require further investigation. Understanding secretory cell

246 diversity in the context of IL-13 stimulation will be crucial in understanding asthma pathology.

247 Our data underline the increasing recognition of epithelial cell heterogeneity, suggesting 248 that airway epithelial subsets may be more precisely described by sets of molecular markers 
rather than using traditional approaches for defining ciliated, basal and secretory cells based on morphology and/or use of more limited sets of markers (26). Traditionally, nomenclature is based principally on histologic criteria $(5,6)$ that fail to capture the heterogeneity evident from

252 scRNA-seq (7-11) or antibody panels. Our protocol provides a working method for classifying

253 airway epithelial subsets, and we expect that additional reagents can be added to this panel to

254 further subdivide major subsets and identify other smaller populations, such as ionocytes.

255 Furthermore, use of standard sets of molecular markers such as those developed here will 256 promote clearer communication and allow for more meaningful comparisons across studies.

257 We coupled flow cytometric cell sorting with gene expression analysis and identified 258 mRNA transcripts not detected in our scRNA-seq experiment plus several miRNAs. Although 259 scRNA-seq is revealing airway epithelial cell transcriptomes in unprecedented resolution,

260 current technologies have limited sensitivity and do not reliably detect low-abundance

261 transcripts (e.g. transcription factors) that may have significant impact on cell specification and

262 in disease. Furthermore, available scRNA-seq techniques are generally not suited for analyzing 263 mRNA variants or small RNAs, such as miRNAs. Therefore, our sorting panel may contribute to 264 deeper cataloging of airway epithelial subset transcriptomes. Additionally, our panels could be 265 coupled with downstream epigenetic and proteomic analyses to further understand the 266 specification and/or function of airway epithelial subsets in human health and disease.

267 There is also potential to build on the protocols we have developed. For example,

268 although flow cytometric analysis of clinical samples was not performed, published scRNA-seq 269 datasets suggest that the panels we developed could be useful for analyzing disaggregated 270 cells from human airways (7, 9-11). Furthermore, although our study used a 10-parameter, 8-

271 fluorochrome approach, application of an increased panel is viable. Future refinement and the

272 addition of other markers for rarer epithelial subtypes (e.g. cystic fibrosis transmembrane

273 conductance regulator (CFTR)-expressing ionocytes and doublecortin like kinase 1 (DCLK1)-

274 expressing tuft cells (7-10)) may permit characterization of the null or minor $(<1 \%)$ populations 
275 reported here. Additionally, combining the epithelial panel with existing panels for immune cells

276 and other non-epithelial cells will permit a more comprehensive examination of lung

277 development, airway inflammatory and immune responses, and a variety of disease states.

278 Mass cytometry (27) or use of oligonucleotide-barcoded antibodies together with single cell

279 sequencing (28) also promise to allow for more extensive panels of markers that could further

280 expand our approach to increase our understanding of the function of specific subsets and their

281 heterogeneity.

282 In summary, we have leveraged scRNA-seq datasets to develop flow cytometry panels

283 for characterizing subpopulations of airway epithelial cells. These panels identified major airway

284 epithelial cell subsets, revealed molecular heterogeneity within these populations, and permitted

285 analysis of low abundance transcripts and miRNAs. We envisage that these panels and their

286 future refinements will be powerful tools for interrogating airway epithelial biology.

\section{Acknowledgements}

289 We thank Joshua Pollack for his help analyzing Drop-seq data. We also thank the UCSF Nikon

290 Imaging Center and Laboratory for Cell Analysis for advice and assistance with microscopy and

291 flow cytometry, respectively. 


\section{References}

293 1. Maecker HT, McCoy JP, Nussenblatt R. Standardizing immunophenotyping for the Human 294 Immunology Project. Nature Reviews Immunology 2012;12:191-200.

295 2. Tighe RM, Redente EF, Yu Y-R, Herold S, Sperling Al, Curtis JL, Duggan R, Swaminathan

296 S, Nakano H, Zacharias WJ, Janssen WJ, Freeman CM, Brinkman RR, Singer BD,

297 Jakubzick CV, Misharin AV. Improving the Quality and Reproducibility of Flow Cytometry in the Lung. An Official American Thoracic Society Workshop Report. Am J Respir Cell Mol

3. Bonser LR, Erle DJ. The airway epithelium in asthma. Adv Immunol 2019;142:1-34.

4. Bonser LR, Erle DJ. Airway Mucus and Asthma: The Role of MUC5AC and MUC5B. J Clin Med 2017;6:

5. Rhodin J. LXVII Ultrastructure of the Tracheal Ciliated Mucosa in Rat and Man. Annals of Otology, Rhinology \& Laryngology 1959;68:964-974.

6. Widdicombe JH. Early Studies on the Surface Epithelium of Mammalian Airways. American Journal of Physiology-Lung Cellular and Molecular Physiology 2019;doi:10.1152/ajplung.00240.2019.

7. Plasschaert LW, Žilionis R, Choo-Wing R, Savova V, Knehr J, Roma G, Klein AM, Jaffe AB. A single-cell atlas of the airway epithelium reveals the CFTR-rich pulmonary ionocyte. Nature 2018;560:377.

8. Montoro DT, Haber AL, Biton M, Vinarsky V, Lin B, Birket SE, Yuan F, Chen S, Leung HM, Villoria J, Rogel N, Burgin G, Tsankov AM, Waghray A, Slyper M, Waldman J, Nguyen L, 
9. Ordovas-Montanes J, Dwyer DF, Nyquist SK, Buchheit KM, Vukovic M, Deb C, Wadsworth MH, Hughes TK, Kazer SW, Yoshimoto E, Cahill KN, Bhattacharyya N, Katz HR, Berger B, Laidlaw TM, Boyce JA, Barrett NA, Shalek AK. Allergic inflammatory memory in human respiratory epithelial progenitor cells. Nature 2018;560:649.

10. Duclos GE, Teixeira VH, Autissier P, Gesthalter YB, Reinders-Luinge MA, Terrano R, Dumas YM, Liu G, Mazzilli SA, Brandsma C-A, Berge M van den, Janes SM, Timens W, Lenburg ME, Spira A, Campbell JD, Beane J. Characterizing smoking-induced transcriptional heterogeneity in the human bronchial epithelium at single-cell resolution. Science Advances 2019;5:eaaw3413.

11. García SR, Deprez M, Lebrigand K, Cavard A, Paquet A, Arguel M-J, Magnone V, Truchi M, Caballero I, Leroy S, Marquette C-H, Marcet B, Barbry P, Zaragosi L-E. Novel dynamics of human mucociliary differentiation revealed by single-cell RNA sequencing of nasal epithelial cultures. Development 2019;146:.

12. Maestre-Batlle D, Pena OM, Hirota JA, Gunawan E, Rider CF, Sutherland D, Alexis NE, Carlsten C. Novel flow cytometry approach to identify bronchial epithelial cells from healthy

332 13. Griggs TF, Bochkov YA, Basnet S, Pasic TR, Brockman-Schneider RA, Palmenberg AC, 333 Gern JE. Rhinovirus C targets ciliated airway epithelial cells. Respir Res 2017;18:84.

334 14. Rock JR, Onaitis MW, Rawlins EL, Lu Y, Clark CP, Xue Y, Randell SH, Hogan BLM. Basal 335 cells as stem cells of the mouse trachea and human airway epithelium. PNAS 2009;106:12771-12775.

15. Koh KD, Siddiqui S, Cheng D, Bonser LR, Sun DI, Zlock LT, Finkbeiner WE, Woodruff PG, 338 Erle DJ. Efficient RNP-Directed Human Gene Targeting Reveals SPDEF is Required for IL13-Induced Mucostasis. Am J Respir Cell Mol Biol 2019;doi:10.1165/rcmb.2019-0266OC. 
16. Fulcher ML, Gabriel S, Burns KA, Yankaskas JR, Randell SH. Well-Differentiated Human Airway Epithelial Cell Cultures. In: Picot J, editor. Human Cell Culture Protocols Totowa, NJ: Humana Press; 2005. p. 183-206.doi:10.1385/1-59259-861-7:183.

17. Whitcutt MJ, Adler KB, Wu R. A biphasic chamber system for maintaining polarity of differentiation of cultured respiratory tract epithelial cells. In Vitro Cell Dev Biol 1988;24:420428.

18. Bonser LR, Zlock L, Finkbeiner W, Erle DJ. Epithelial tethering of MUC5AC-rich mucus impairs mucociliary transport in asthma. J Clin Invest 2016;126:2367-2371.

19. Macosko EZ, Basu A, Satija R, Nemesh J, Shekhar K, Goldman M, Tirosh I, Bialas AR, Kamitaki N, Martersteck EM, Trombetta JJ, Weitz DA, Sanes JR, Shalek AK, Regev A, McCarroll SA. Highly Parallel Genome-wide Expression Profiling of Individual Cells Using Nanoliter Droplets. Cell 2015;161:1202-1214.

20. Lukinavičius G, Reymond L, D'Este E, Masharina A, Göttfert F, Ta H, Güther A, Fournier M, Rizzo S, Waldmann H, Blaukopf C, Sommer C, Gerlich DW, Arndt H-D, Hell SW, Johnsson K. Fluorogenic probes for live-cell imaging of the cytoskeleton. Nature Methods 2014;11:731-733.

21. Oltean A, Schaffer AJ, Bayly PV, Brody SL. Quantifying Ciliary Dynamics during Assembly Reveals Stepwise Waveform Maturation in Airway Cells. Am J Respir Cell Mol Biol 2018;59:511-522.

22. Christenson SA, van den Berge M, Faiz A, Inkamp K, Bhakta N, Bonser LR, Zlock LT, Barjaktarevic IZ, Barr RG, Bleecker ER, Boucher RC, Bowler RP, Comellas AP, Curtis JL, Han MK, Hansel NN, Hiemstra PS, Kaner RJ, Krishnanm JA, Martinez FJ, O'Neal WK, Paine R, Timens W, Wells JM, Spira A, Erle DJ, Woodruff PG. An airway epithelial IL-17A response signature identifies a steroid-unresponsive COPD patient subgroup. J Clin Invest 2019;129:169-181. 
23. Pan J, Adair-Kirk TL, Patel AC, Huang T, Yozamp NS, Xu J, Reddy EP, Byers DE, Pierce RA, Holtzman MJ, Brody SL. Myb permits multilineage airway epithelial cell differentiation. Stem Cells 2014;32:3245-3256.

24. Song R, Walentek P, Sponer N, Klimke A, Lee JS, Dixon G, Harland R, Wan Y, Lishko P, Lize M, Kessel M, He L. miR-34/449 miRNAs are required for motile ciliogenesis by repressing cp110. Nature 2014;510:115-120.

25. Biton M, Levin A, Slyper M, Alkalay I, Horwitz E, Mor H, Kredo-Russo S, Avnit-Sagi T, Cojocaru G, Zreik F, Bentwich Z, Poy MN, Artis D, Walker MD, Hornstein E, Pikarsky E, Ben-Neriah Y. Epithelial microRNAs regulate gut mucosal immunity via epithelium-T cell crosstalk. Nature Immunology 2011;12:239-246.

26. Bonser LR, Erle DJ. Putting Mucins on the Map. American Journal of Respiratory and Critical Care Medicine 2018;doi:10.1164/rccm.201809-1818ED.

27. Bandura DR, Baranov VI, Ornatsky OI, Antonov A, Kinach R, Lou X, Pavlov S, Vorobiev S, Dick JE, Tanner SD. Mass cytometry: technique for real time single cell multitarget immunoassay based on inductively coupled plasma time-of-flight mass spectrometry. Anal Chem 2009;81:6813-6822.

28. Akkaya B, Miozzo P, Holstein AH, Shevach EM, Pierce SK, Akkaya M. A Simple, Versatile Antibody-Based Barcoding Method for Flow Cytometry. The Journal of Immunology 2016;197:2027-2038.

29. Piperno G, Fuller MT. Monoclonal antibodies specific for an acetylated form of alpha-tubulin

30. Basnet S, Bochkov YA, Brockman-Schneider RA, Kuipers I, Aesif SW, Jackson DJ, recognize the antigen in cilia and flagella from a variety of organisms. $J$ Cell Biol 
391 31. Bønnelykke K, Sleiman P, Nielsen K, Kreiner-Møller E, Mercader JM, Belgrave D, den

392 Dekker HT, Husby A, Sevelsted A, Faura-Tellez G, Mortensen LJ, Paternoster L, Flaaten R, 393 Mølgaard A, Smart DE, Thomsen PF, Rasmussen MA, Bonàs-Guarch S, Holst C, Nohr EA, 394 Yadav R, March ME, Blicher T, Lackie PM, Jaddoe VWV, Simpson A, Holloway JW, Duijts 395 L, Custovic A, et al. A genome-wide association study identifies CDHR3 as a susceptibility 396 locus for early childhood asthma with severe exacerbations. Nat Genet 2014;46:51-55.

397 32. Beane J, Sebastiani P, Liu G, Brody JS, Lenburg ME, Spira A. Reversible and permanent 398 effects of tobacco smoke exposure on airway epithelial gene expression. Genome Biol $399 \quad$ 2007;8:R201.

400 33. Ooi AT, Gower AC, Zhang KX, Vick JL, Hong L, Nagao B, Wallace WD, Elashoff DA, 401 Walser TC, Dubinett SM, Pellegrini M, Lenburg ME, Spira A, Gomperts BN. Molecular 402 Profiling of Premalignant Lesions in Lung Squamous Cell Carcinomas Identifies 403 Mechanisms Involved in Stepwise Carcinogenesis. Cancer Prev Res 2014;7:487-495.

404 34. Shikotra A, Choy DF, Siddiqui S, Arthur G, Nagarkar DR, Jia G, Wright AKA, Ohri CM, 405 Doran E, Butler CA, Hargadon B, Abbas AR, Jackman J, Wu LC, Heaney LG, Arron JR, 406 Bradding P. A CEACAM6-High Airway Neutrophil Phenotype and CEACAM6-High Epithelial 407 Cells Are Features of Severe Asthma. J Immunol 2017;198:3307-3317. 


\begin{tabular}{|c|c|c|c|c|}
\hline Name & Antigen & Cell subset & Description & References \\
\hline $\begin{array}{l}\text { Acetylated } \\
\text { alpha-tubulin }\end{array}$ & TUBA & Ciliated & $\begin{array}{l}\text { Recognizes axonemal alpha-tubulin } \\
\text { acetylated on the epsilon-amino } \\
\text { group of lysine(s), a hallmark of } \\
\text { stable microtubules, which are } \\
\text { enriched in motile cilia }\end{array}$ & $(7,9,10,21,29$ \\
\hline $\begin{array}{l}\text { Cadherin- } \\
\text { related family } \\
\text { member } 3\end{array}$ & CDHR3 & Ciliated & $\begin{array}{l}\text { Calcium-dependent cell adhesion } \\
\text { protein associated with ciliogenesis } \\
\text { and asthma; receptor for Rhinovirus } \\
\text { C }\end{array}$ & $(9,10,13,30,3$ \\
\hline \multirow{2}{*}{$\begin{array}{l}\text { integrin subunit } \\
\text { alpha } 6\end{array}$} & CD49f/ & \multirow[t]{2}{*}{ Basal } & \multirow{2}{*}{$\begin{array}{l}\text { Integral membrane protein of the } \\
\text { integrin alpha chain family; function } \\
\text { uncharacterized in the airway }\end{array}$} & \multirow[t]{2}{*}{$(10,14)$} \\
\hline & ITGA6 & & & \\
\hline $\begin{array}{l}\text { Nerve growth } \\
\text { factor receptor }\end{array}$ & $\begin{array}{l}\text { CD271/ } \\
\text { NGFR }\end{array}$ & Basal & $\begin{array}{l}\text { Cell surface receptor localized to } \\
\text { basal cells of unknown function in } \\
\text { the airway }\end{array}$ & $(7,14)$ \\
\hline $\begin{array}{l}\text { CEA cell } \\
\text { adhesion } \\
\text { molecule } 5\end{array}$ & $\begin{array}{l}\text { CD66c/ } \\
\text { CEACAM5 }\end{array}$ & Secretory & $\begin{array}{l}\text { Cell surface glycoprotein upregulated } \\
\text { after smoking cessation and linked to } \\
\text { lung squamous cell carcinoma }\end{array}$ & $(9,10,32,33)$ \\
\hline $\begin{array}{l}\text { CEA cell } \\
\text { adhesion } \\
\text { molecule } 6\end{array}$ & $\begin{array}{l}\text { CD66e/ } \\
\text { CEACAM6 }\end{array}$ & Secretory & $\begin{array}{l}\text { Cell surface glycoprotein associated } \\
\text { with severe asthma and upregulated } \\
\text { after smoking cessation }\end{array}$ & $(7,9,10,32,34$ \\
\hline Tetraspanin 8 & TSPAN8 & Goblet & $\begin{array}{l}\text { Cell surface glycoprotein of unknown } \\
\text { function in the airway }\end{array}$ & $(9,10)$ \\
\hline Mucin 5AC & MUC5AC & Goblet & $\begin{array}{l}\text { Secreted, gel-forming glycoprotein } \\
\text { associated with mucus dysfunction in } \\
\text { chronic lung disease }\end{array}$ & $(4,9,10)$ \\
\hline
\end{tabular}




\section{Figure Legends}

412 Figure 1: Identification of cell-specific markers for flow cytometry. $(A)$ Human bronchial

413 epithelial cells (HBECs) grown in the absence (cyan histogram) or presence of interleukin-13

414 (IL-13; magenta histogram) were stained using antibodies against cell subset specific markers.

415 Positive staining was determined by comparing the same sample stained with an appropriate

416 isotype control (grey histogram). (B) Comparison of positive staining for cell-subset-specific

417 markers from unstimulated and IL-13-stimulated HBECs $(n=5$; each donor is represented by a

418 different color). Significance was evaluated using a $t$-test: ns, nonsignificant; * $P<0.05$; and ${ }^{* *}$, $419 \quad P<0.01$.

421 Figure 2: Characterization of airway epithelial cells subsets and IL-13 stimulation using

422 an analytical flow cytometry panel. HBECs $(n=3)$ were cultured with or without IL-13 and then

423 processed for multicolor flow cytometry. ( $A-L)$ Results from 3,000 cells from each donor were

424 combined and analyzed by t-Distributed Stochastic Neighbor Embedding (tSNE). tSNE plots are

425 colored to show cells that stained for the ciliated cell markers (red) TUBA $(A)$ and CDHR3 $(B)$,

426 the basal cell markers (blue) NGFR $(C)$ and ITGA6 $(D)$, and the secretory cell markers (green)

427 CEACAM6 $(E)$, CEACAM5 $(F)$, TSPAN8 $(G)$, and MUC5AC $(H)$. Forward scatter FSC $(J)$ and

428 side scatter SSC $(K)$ are represented as a continuum from low (blue) to high (red). Cells came

429 from unstimulated (-) or IL-13-stimulated cultures $(K)$ from three donors $(L)$. (M-Q) Gating

430 strategy to identify airway epithelial subsets from unstimulated (IL-13-) and IL-13-stimulated (IL-

431 13+) HBECs. Doublets $(M)$ and debris $(M)$ were removed, and resulting singlets were gated on

432 NGFR and TUBA (O). Subsequently, TUBA $^{-}$NGFR $^{-}$singlets were gated on ITGA6 and

433 CEACAM6 $(P)$. ITGA6 ${ }^{-}$CEACAM6 $^{+}$cells were then gated on MUC5AC and TSPAN8 $(Q) .(R)$

434 Comparison of cell subsets (>1\%) from unstimulated (IL-13-; cyan) and IL-13-stimulated (IL-

$43513+$; magenta) HBECs ( $n=3$; each donor is represented by a different point). Ciliated cell 
436 markers are colored blue, basal cell markers red, and secretory cell markers green. "Null"

437 indicates cells that did not stain with any of the eight markers and "Other" indicates totals for all

438 subsets representing $<1 \%$ of total cells. Significance was evaluated using Student's $t$-test: ns,

439 not significant; ${ }^{*}, P<0.05 ;{ }^{* *}, P<0.01$.

441 Figure 3: Flow cytometric sorting of HBEC subsets. Prior to processing for flow cytometry,

442 HBECs cultured in the absence or presence of IL-13 were stained with SiR-tubulin. SiR-tubulin-

443 stained cells were trypsinized, stained with a cell viability dye, and sorted by FACS. (A-E)

444 Gating strategy for flow cytometric cell sorting of unstimulated (IL-13-) and IL-13-stimulated (IL-

$44513+)$ HBECs. After selection of singlets $(A)$ and live cells $(B)$, cells were gated on SiR-tubulin

446 and NGFR staining (C). SiR-tubulin ${ }^{-}$cells were gated on NGFR and CEACAM6 (D). NGFR ${ }^{-}$

447 CEACAM6 $^{+}$cells were gated on MUC5AC and TSPAN8 $(E) .(F, G)$ To validate SiR-tubulin

448 staining, SiR-tubulin ${ }^{+}$cells were fixed in paraformaldehyde, immobilized to slides by cytospin,

449 stained with TUBA (cyan), and counterstained with DAPI (blue). Images show cells from

450 unstimulated (IL-13-, F) and IL-13-stimulated (IL-13+, G) cultures with TUBA-stained cilia

451 (found in 58/60 cells examined). Scale bar $=10 \mu \mathrm{M} .(H)$ Quantitative real-time PCR analysis of

452 sorted cell subpopulations. Mean expression values calculated from triplicate experiments with

453 different donors were normalized to the maximum expression of the gene in any cell type $(0-1$ :

454 white-red). 
bioRxiv preprint doi: https://doi.org/10.1101/2020.04.20.051383; this version posted April 21, 2020. The copyright holder for this preprint (which was not certified by peer review) is the author/funder, who has granted bioRxiv a license to display the preprint in perpetuity. It is made available under aCC-BY-NC-ND 4.0 International license.

Figure 1

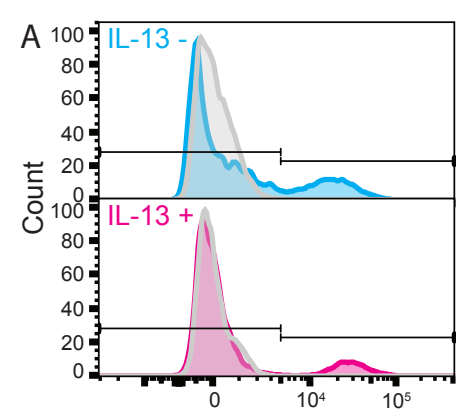

TUBA
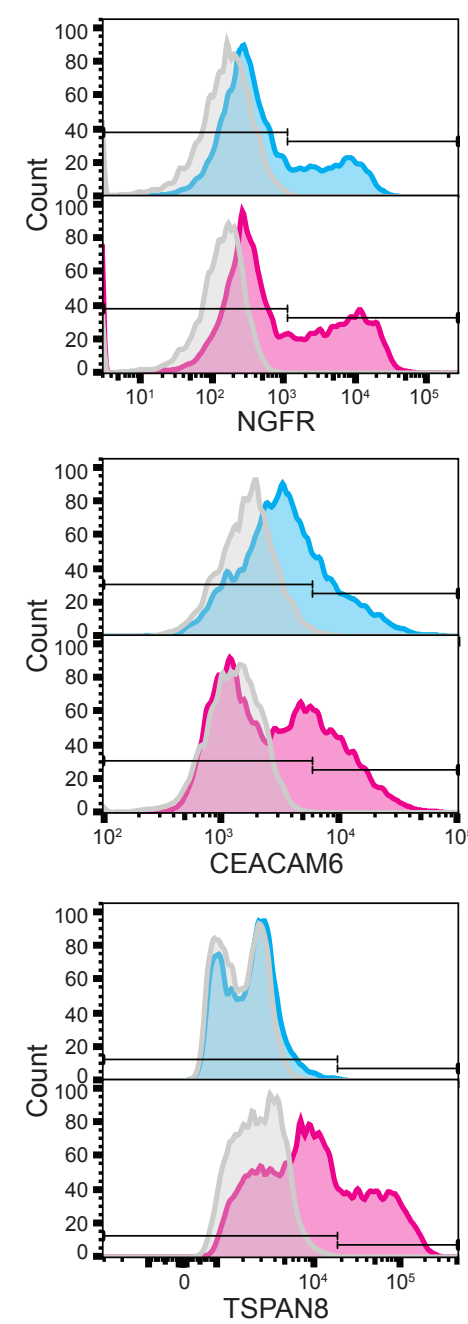

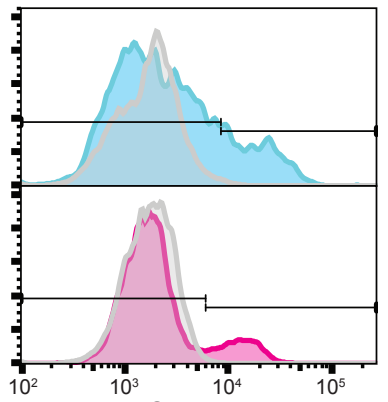

CDHR3
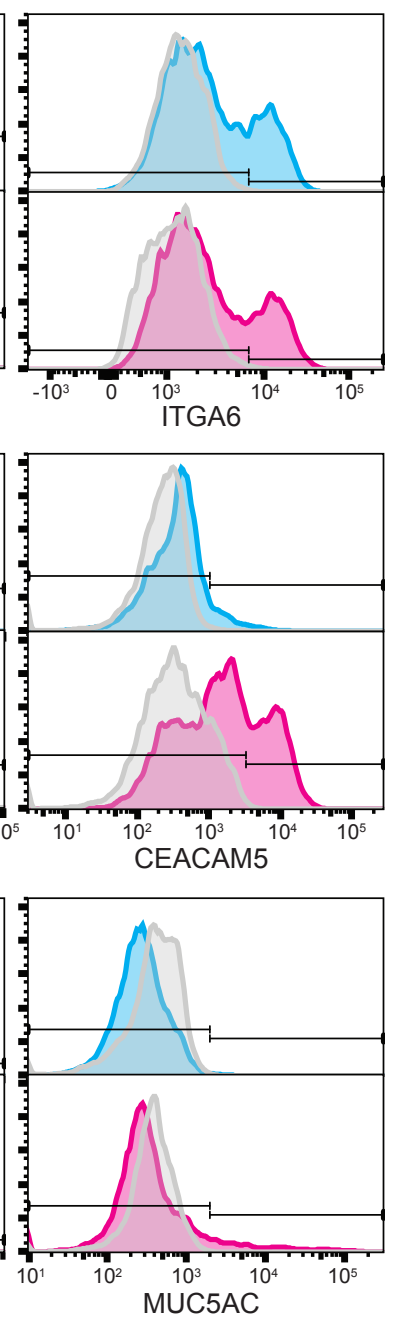

B
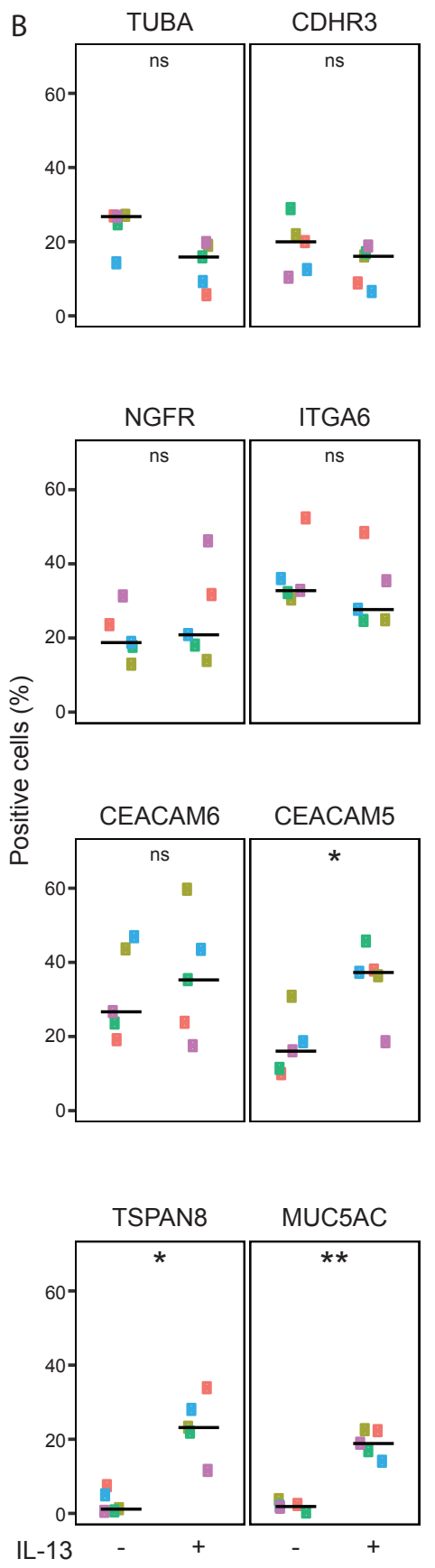
bioRxiv preprint doi: https://doi.org/10.1101/2020.04.20.051383; this version posted April 21, 2020. The copyright holder for this preprint (which was not certified by peer review) is the author/funder, who has granted bioRxiv a license to display the preprint in perpetuity. It is made available under aCC-BY-NC-ND 4.0 International license.

Figure 2
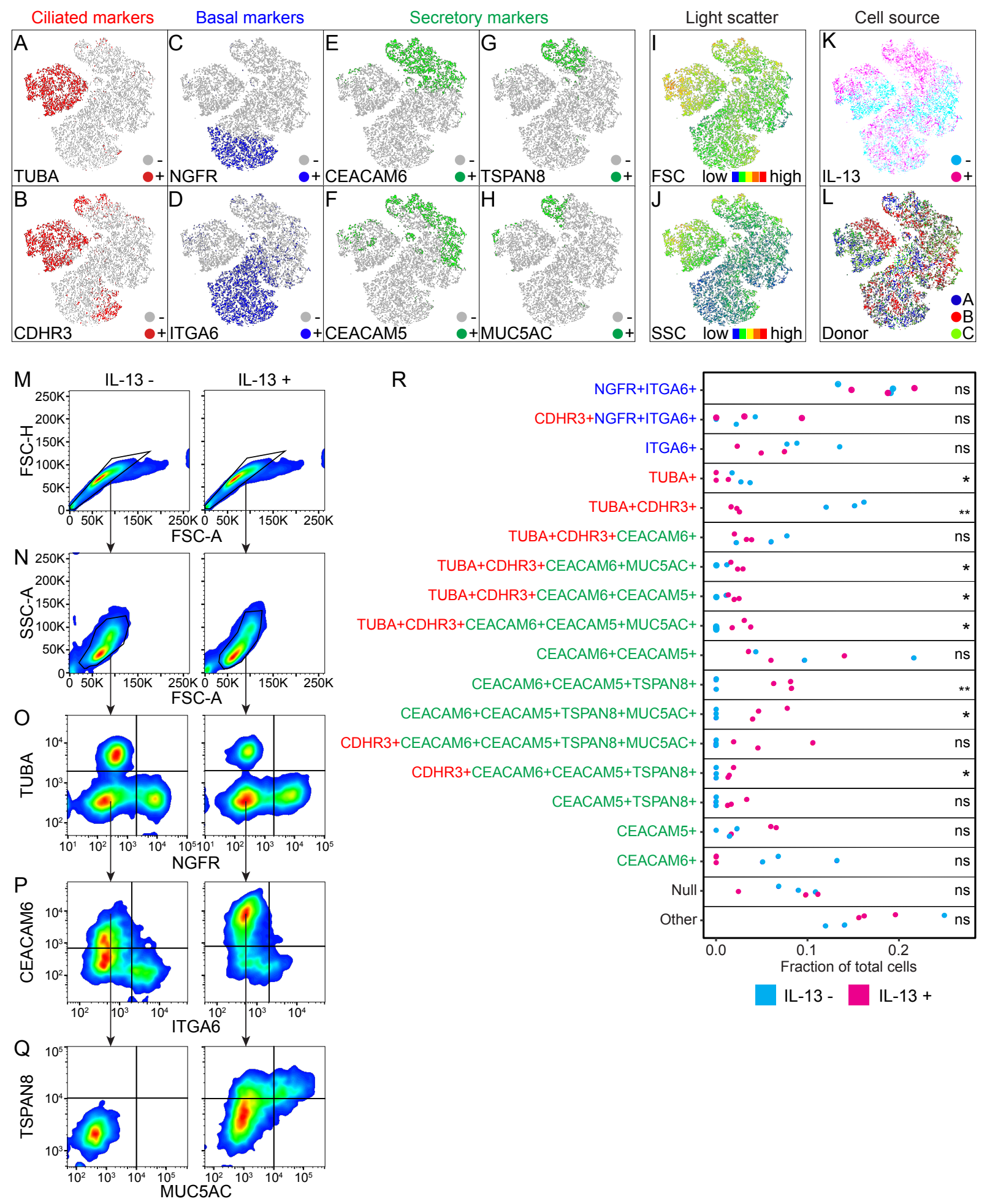
Figure 3

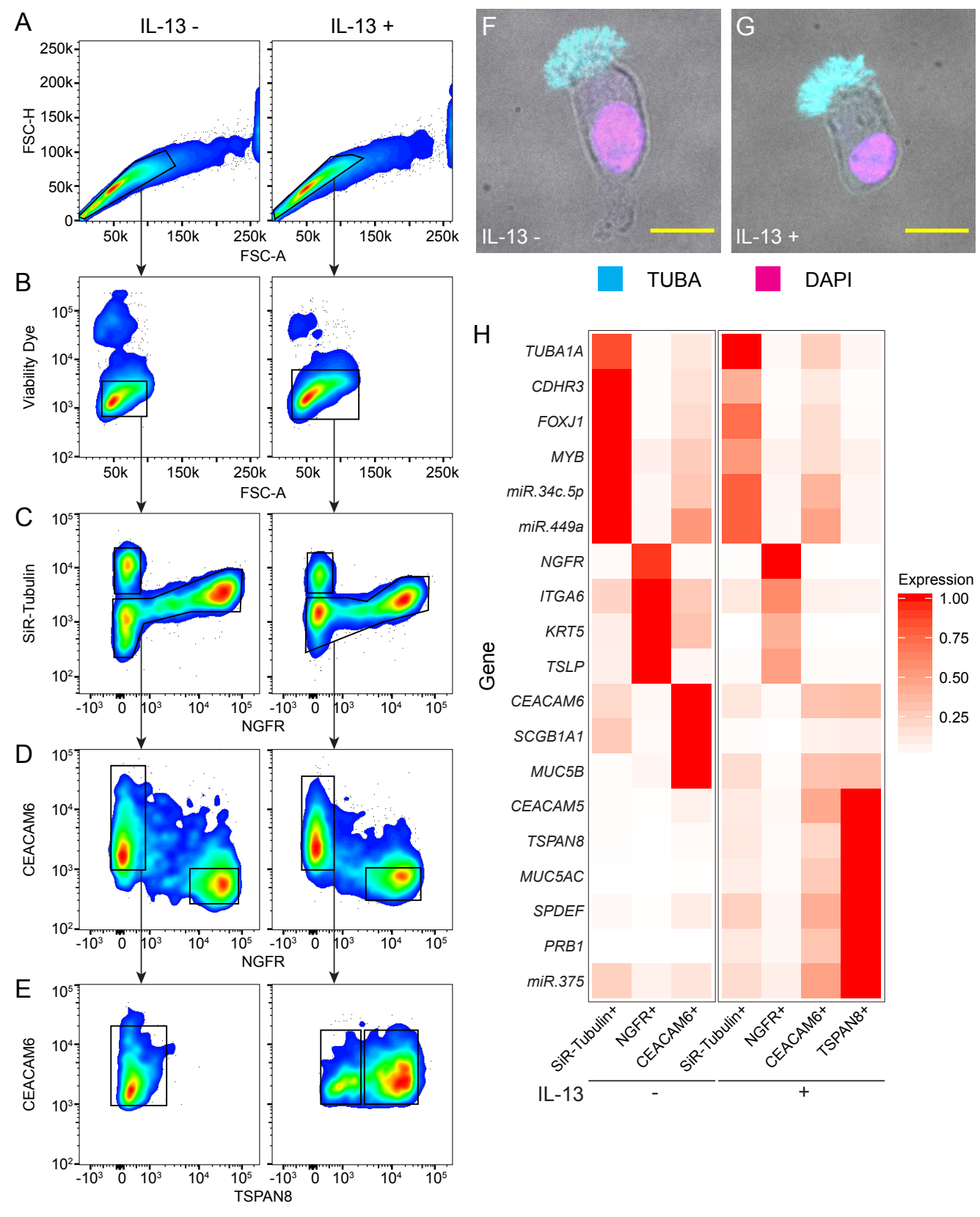

